\title{
An Innovative Antiseptic, Antiperspirant and Deodourant Diaper for the Older and Frail Older People Suffering from Urinary Incontinence
}

\author{
Elaine Wat1,2, Alex W. L. Lin ${ }^{3}$, Cyrus Mak, Ivan Lam4, Clara Bik-San Lau, ${ }^{1,2}$, \\ Frency Sau-Fun Ng33, Patrick Chi-Leung Hui ${ }^{3}$, Ping-Chung Leung ${ }^{1,2 *}$ \\ ${ }^{1}$ Institute of Chinese Medicine, The Chinese University of Hong Kong, Hong Kong \\ ${ }^{2}$ Partner State Key Laboratory of Phytochemistry and Plant Resources in West China, The Chinese University of Hong Kong, \\ Hong Kong \\ ${ }^{3}$ Institute of Textiles and Clothing, The Hong Kong Polytechnic University, Hong Kong \\ ${ }^{4}$ Neighbourhood Advice-Action Council, Harmony Manor, Hong Kong \\ Email: *pingcleung@cuhk.edu.hk
}

How to cite this paper: Wat, E., Lin, A.W.L., Mak, C., Lam, I., Lau, C.B.-S., Ng, F.S.-F., Hui, P.C.-L. and Leung, P.-C. (2017) An Innovative Antiseptic, Antiperspirant and Deodourant Diaper for the Older and Frail Older People Suffering from Urinary Incontinence. Advances in Aging Research, 6, 29-37.

https://doi.org/10.4236/aar.2017.62004

Received: January 9, 2017

Accepted: March 3, 2017

Published: March 6, 2017

Copyright $\odot 2017$ by authors and Scientific Research Publishing Inc. This work is licensed under the Creative Commons Attribution International License (CC BY 4.0).

http://creativecommons.org/licenses/by/4.0/

\begin{abstract}
Background: Urinary Incontinence is a common symptom among the older and frail older people. Apart from affecting the quality of life and skin complications, the demand on assistance could be too high for any sufferer. While conservative means of treatment do not work, special incontinence apparel could be a good compromise. Objective: To create an absorbent, antiseptic, antiperspirant and deodourant diaper for the older and dependent people suffering from urinary incontinence. Material and Methods: Antiperspirant and antiseptic medicinal materials have been reported in Traditional Chinese Medicine and two herbs were screened out to provide the required effects. A combination of Fraxini Cortex, Calamine and Zinc oxide made in powder forms was impregnated into a pocket of the diaper. Laboratory tests were performed to confirm the antiseptic, antiperspirant and deodourant effects of the materials. A self-control clinical trial on the diaper was organized in an elderly home. Results: Antibacterial effects against Staphylococcus, E. coli and Candida were proven. Antiperspirant effects were confirmed using acetylcholinesterase inhibitor testings. Volunteers using the Sudoscan machine further demonstrated the weak antiperspirant effects of the herbs. A pilot study on 31 dependent diaper users gave positive feedbacks of more comfort, less leakage, odour and better skin conditions. The overall satisfaction reached $79 \%$. Conclusion: A special diaper with antiseptic, antiperspirant and deodourant effects could be created with in-expensive herbal powder impregnated and
\end{abstract}


could be recommended to the older and frail older people with urinary incontinence.

\section{Keywords}

Urinary Incontinence, Older And Frail Older, Toilet Assistance, Rehabilitation, Adult Diaper

\section{Introduction}

Older and frail older people often suffer from incontinence. This problem is most common among frail older people living in elderly homes which might not be provided with sufficient carers. Overnight wetting of diapers which serve as compromising treatment frequently leads to perineal dermatitis and the poor micro-environment often leads to contacting pressure injuries (ulcers). Despite consequences of unhealthiness and deteriorating quality of life, these frail older people are not given special attention over the incontinence [1] [2].

When the apparently simple "wetting" phenomenon is seriously analysed, many specific problems are revealed. They are:

i) Overflow of urine, which is the source of discomfort and demand for much manpower support in tedious apparel care.

ii) Perineal dermatitis, which could result from the poor micro-environment, bacterial and fungal infections.

iii) Pressure injuries, which are consequences of dermatitis leading to skin abrasions and ulcerations resulting even from minor rubs and contact stretches [3].

iv) Local infections, which are particularly prone in the perineal region because of the faecal outlet [3].

v) Foul odour production resulting from the combination of bacterial and fungal flora, putrefaction activities arising from the unhygienic environment and sweat gland irritations [4].

vi) Sweat gland hyperactivity reacting to the poor microenvironment [5].

A pilot study was therefore planned and the aim was to create a special diaper for the older and frail older people suffering from urinary incontinence to prevent complications arising from over-night and persistent wetting of the perineal region. Topical Traditional Chinese Medicine could be considered since many medicinal herbs have been reported to be antiseptic, antiperspirant and anti-allergic. Herbal products more over are not expensive.

The innovative Diaper should therefore possess the following properties: effectively absorbent, antiseptic, antiperspirant and deodourant.

With regard to the absorbent ability of the diaper, the material involved, its fabrication and design would require the critical analysis of the textile and apparel experts.

With regard to the other requirements, we looked forward to medicinal herbs 
that had been reported to be antibacterial and antiperspirant. They needed to be tested in biological platforms and then in clinical applications. The deodouring effects could be tested in reputable special laboratories and in the subsequent clinical trials. The medicinal herbs, in extract powder form, were to be implanted into the diapers which would be given to volunteers in a clinical pilot study.

\section{Medicinal Materials}

Traditional Chinese medicine has reported a number of medicinal material (including herbs) having antiseptic, antiperspirant and deodourant effects.

The selected material included two herbs and two solid powders.

The medicinal herbs are:

i) Mori Follium (Mulberry leaves) is the leaves of the mulberry tree have been reported since the Ming Dynasty in China to be an effective antiperspirant (本草綱目李時珍 Li Shi-Zhen, Compendium of Materia Medica) when used as an oral concoction. Using Mori Follium as a local agent has not been reported [6].

ii) Fraxini Cortex. The cortex of the plant has been used systemically as an antiperspirant. In the laboratory, special extracts of Fraxinus Rhynchophylla have been proven to have antiperspirant effects through fluorescence tests using the protein constitutions of human skin and comparing with a potent in-organic antiperspirant aluminum polychloride [7].

The solid powders are:

iii) Calamine powder. Although calamine lotion has been known as a common inert and perhaps anti-allergic topical agent among family physicians dermatologists, calamine powder in Traditional Chinese medicine is advocated as an anti-inflammatory, anti-allergic, deodourant and antiperspirant agent. The powder is obtained from a soft stone and is found to contain silicone and traces of Zinc Oxide [8].

iv) Zinc oxide powder. The Zinc oxide cream or paste has been widely used in clinical practice as an inert cleaning material for irritable skin among babies and dependents requiring diapers. Zinc oxide has also been utilized in Traditional medicine as a dry powder created from a soft stone for itchy skin and dermatitis. It is antiseptic and anti-allergic [9]

\subsection{The Diaper}

A heavy duty absorbent diaper of mixed cotton and synthetic material was chosen (Figure 1). The medicinal herbs were prepared as aqueous extracts in the standard way (boiling for two hours followed by filtering out). After dehydration and drying processes, the extracts were converted to the powder form.

A special window was created behind the inner layer of the diaper leading the way into a pocket which held 1 gram each of the powders, viz, of Mori Follium, Fraxini Cortex, Calamine and Zinc oxide. The medicinal powders were well concealed so that there would be no direct contact with the perineal skin. After 
Diaper Before use

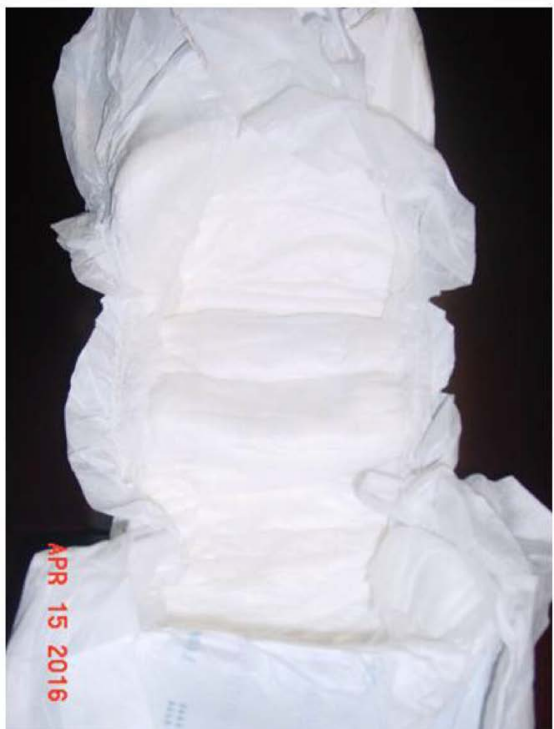

Figure 1. The Diaper before and after application for six hours.

full soaking with urine, the powders would diffuse out to achieve direct interactions with the micro-environment [10] [11].

\subsection{Design of the Study}

The study is designed to consist of preliminary Laboratory platform experiments to confirm the antiseptic, antiperspirant and deodourant effects of the medicinal materials; thence clinical studies to test the antiperspirant effects and the overall improvements in the quality of life of the dependent users.

\subsubsection{Laboratory Studies}

i) Prevention of Sepsis:

Bacteriological tests for the common pathogens of the perineal region [12].

ii) Control of Sweating:

Sweating involves complex mechanisms dependent on the sensitivity and activity of cellular tissues within the sweat glands which also responds to neurological messages sent from the cerebrum along the autonomic nerves. Platform study therefore includes (a) Direct explorations on the direct effects of the medicinal agents on the cellular activities, and (b) Explorations on the cholinergic responses of the glandular cells to neurological messages [13] [14].

iii) Deodourant effects:

Special laboratory tests were performed to verify the deodouring effects of the agents against specific odours of ammonia, acetic acid, hydrogen sulphide and methyl mercaptan [15] [16]

\subsubsection{Clinical Testings}

i) Antiperspirant effects of the medicinal herbs

A convenient sweating assessment machine-the Sudoscan, was utilized as an objective tool to assess the state of sweating in the soles of volunteers before and 
after they bathed their feet in a warm pool of herbal extracts [17] [18].

ii) A pilot clinical trial on dependent older and severely disabled people using the innovative herbal extract impregnated diapers.

Volunteers belonging to the frail older group and disable were recruited in an elderly home to try the special diaper for a fixed period of six hours per day for five days, comparing the different experiences of comfort, skin situations, and odour, between the old and new diapers [19].

\section{Results}

\subsection{Laboratory Studies}

Prevention of Sepsis-both Mori Follium and Fraxini Cortex extracts effectively killed strains of Staphylococcus aureus, E. Coli and Candida Fungus. (Special laboratory report from Bacteriological Laboratory of Faculty of Medicine Jinan University Guangzhou using the standard bacteriological cultural requirements) [20].

Control of Sweating. Sweating is initiated through the release of acetylcholine $(\mathrm{ACH})$ via a central control transmitted along the sympathic system. $\mathrm{ACH}$ is deactivated by a specific enzyme $\mathrm{ACH}$ esterase. The cellular activity of sweat gland can be revealed through the assessment of ACH esterase activities under the influence of herbal agents (i.e. Mori Follium and Fraxini Cortex) [21].

The results showed that the herbal extracts enhanced $\mathrm{ACH}$ esterase activities. Full report is being prepared for publication.

Deodorant Effects. Results done in "Expert Japanese Laboratory for deodorization testing" in Shanghai showed very good deodouring effects in Ammonia, Acetic acid, Hydrogen Sulphide and Methyl mercaptan chambers [16]. Figure 2 showed the test results.

\subsection{Clinical Studies}

Sweating Control using the Sudoscan

Sudoscan uses low Direct Current Stimulation to stimulate topical sweating from hands and feet, then chloride ions are extracted from the sweat to create a current when the electrically charged ions encounter specific electrodes. Sudoscan then measures the electrochemical skin conductance (ESC) of the hands and feet through reverse iontophoresis, and the ESC readings indicate the extensiveness of sweating [22]. In the trial, comparing with pre-treatment with the herbal extracts, Sudoscan tests showed a $15.3 \%$ reduction in sweat production after 15 minutes of topical immersion in the herbal bath. A full report has been published. [22].

A pilot trial recruited 31 severely disabled volunteers who required over-night diapers. They wore the medicinal herbs bearing diapers in the Elderly Rehabilitation Home for 5 days, six hours per day and subjectively compared their experience on the special apparel. Feedback and questionnaires were obtained from the volunteers themselves and their immediate attendants. Compared with the diapers they used to wear, majority of volunteers appreciated the trial diapers 


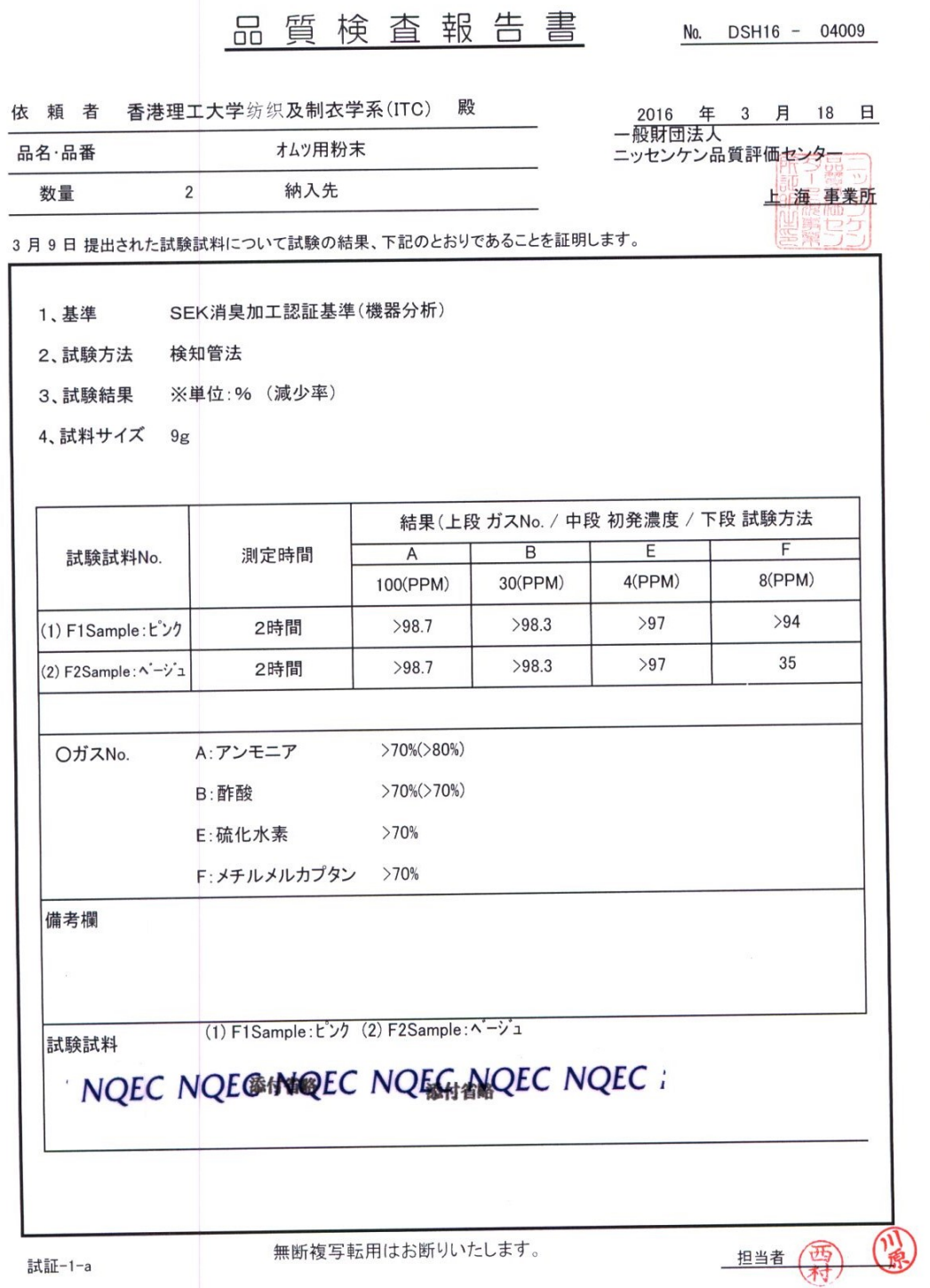

Figure 2. Dedorant effects of the Herbal Formulae (In Japanese).

which absorbed urine well, reduced unpleasant odour, gave better perineal comfort and less itching. No ulceration in the perineal region was found.

Table 1 gives a summary of the results of the clinical trial.

One additional safe-guard measure has been done to eliminate the possibility of allergic reactions arising from the medicinal herbs in topical skin contacts. Using test Kits (Mattek Corporation) and (Epi Derm, EPI 200) to verify whether the extracts could cause allergic reactions showed no allergic responses to the herbal extracts

\section{Discussion}

Urinary incontinence has been defined by the International Society as "any urinary leakage" [1] and it is a common symptom not only among old people but 
Table 1. 31 subjects in a self-control study: overall results of evaluation after completion of the trial use of special diapers.

\begin{tabular}{ccc}
\hline & Special Diaper & Diaper without Medicinal Material \\
\hline Leakage & $5 \%$ & $90 \%$ \\
Comfort & $90 \%$ & $50 \%$ \\
Foul smelling & $20 \%$ & $70 \%$ \\
Healthy skin condition & $90 \%$ & $60 \%$ \\
Overall Satisfaction & Much Better 79\% & \\
\hline
\end{tabular}

also among those suffering from paraplegia. It has been estimated that $30 \%$ $40 \%$ people over 65 years of age living in their own accommodations suffer from incontinence, while those living in nursing homes have an even higher prevalence [2]. The problem affects the quality of life of sufferers and causes dependency, sleep disturbances and downgrades the person's dignity and mood [23]. In the busy, possibly crowded settings of old peoples' home, incontinence tends to significantly affect the environmental hygiene and careers' moral [4]. Frail older persons often suffer from co-existing illnesses and co-morbidities which require intensive assistance from health care staff and further deprive them of available caring time.

Under such adverse reality, the creation of rehabilitation devices that could improve the quality of life of the old people with incontinence and possibly relieve the workload of the carers would be very much appreciated. Among community-dwelling older persons, although incontinence pads (diapers) and toileting programs have been commonly used, but the results are disappointing [2].

The creation of a diaper that would prevent leakage, prevent common skin complications like infection and allergy and improve the odour arising from incontinence is an innovative endeavor. The practical value of the diaper needs to be proven through clinical tests and the cost of production must be affordable to the general public.

There are medicinal herbs used in Traditional Medicine for the control of sweating and other medicinal powder for the protection of skin hygiene. When such simple medicinal materials are impregnated into the fabric of a diaper, there is good chance that the perineal skin could be better protected because of the improved dryer micro-environment, the better antiseptic, antiperspirant and deodouring effects [6] [7] [10].

We have started our research in two stages. Firstly the herbal products were subjected to bacterial and biochemical platforms to investigate their antiseptic, antiperspirant and deodourant effects which were all proven effective. Then, a pilot trial conducted in an elderly home to obtain users information directly from the incontinent sufferers and their attendants. The results have been highly encouraging.

\section{Conclusion}

A simple diaper with good absorbent abilities and antiseptic, antiperspirant and deodourant effects could be made with the incorporation of simple medicinal 
powders used in Traditional Medicine. Its value on the quality of life of the incontinent people has been proven among a small group of volunteer users. It is also expected that this simple device would also simplify the supportive role of the carers.

\section{Acknowledgements}

Special gratitude is given to the "8765 Diabetes" Clinical Services which kindly arranged the application of the SUDOSCAN. We also thank the Neighbourhood Advice-Action Council, Harmony Manor and its staff which provided clinical support for the medicinal herbs bearing diapers study.

\section{Funding}

The work was supported by Innovation and Technology Fund of the Government of Hong Kong Special Administrative Region (Project Code: ITS/370/14).

\section{References}

[1] Hannestad, Y.S., Rortveit, G., Sandvik, H., Hunskaar, S. and Norwegian EPINCONT Study (2000) Epidemiology of Incontinence in the County of NordTrøndelag. A Community-Based Epidemiological Survey of Female Urinary Incontinence: The Norwegian EPINCONT Study. Epidemiology of Incontinence in the County of Nord-Trøndelag. Journal of Clinical Epidemiology, 53, 1150-1157. https://doi.org/10.1016/S0895-4356(00)00232-8

[2] Stenzelius, K., Molander, U., Odeberg, J., Hammarstrom, M., Franzen, K., Midlov, P., et al. (2015) The Effect of Conservative Treatment of Urinary Incontinence among Older and Frail Older People: A Systematic Review. Age and Ageing, 44, 736-744. https://doi.org/10.1093/ageing/afv070

[3] Stenzelius, K., Mattiasson, A., Hallberg, I.R. and Westergren, A. (2004) Symptoms of Urinary and Faecal Incontinence among Men and Women 75+ in Relations to Health Complaints and Quality of Life. Neurourology and Urodynamics, 23, 211 222. https://doi.org/10.1002/nau.20030

[4] Andersson, G., Johansson, J.E., Nilsson, K. and Sahlberg-Blom, E. (2008) Accepting and Adjusting: Older Women's Experiences of Living with Urinary Incontinence. Urologic Nursing, 28, 115-121.

[5] Coyne, K.S., Wein, A., Nicholson, S., Kvasz, M., Chen, C.I. and Milsom, I. (2013) Comorbidities and Personal Burden of Urgency Urinary Incontinence: A Systematic Review. International Journal of Clinical Practice, 67, 1015-1033. https://doi.org/10.1111/ijcp.12164

[6] Du, W.X. and Tien, F.Y. (1997) Mulberry Antiperspirant Research. Journal of Tianjin University of Traditional Chinese Medicine, 16, 8.

[7] Xue, Y.F., Zhai, S.X. and Wang, J.X. (2005) Screening of Antiperspiratory Ingredient in Fraxinus rhychophylla. China Surfactant Detergent and Cosmetics, 35, 133-136.

[8] Lui, H., Sun, Z.Q. and Wang, H. (2010) Research Progress on Clinical Application of Calamine. Qilu Pharmaceutical Affairs, 29, 489-490.

[9] Adam, R. (2008) Skin Care of the Diaper Area. Pediatric Dermatology, 25, 427-433. https://doi.org/10.1111/j.1525-1470.2008.00725.x

[10] Antranik, B. (2001) Antiperspirants and Deodorants. Clinics in Dermatology, 19, 398-405. https://doi.org/10.1016/S0738-081X(01)00192-4 
[11] Brown, D.J. and Dattner, A.M. (1998) Phytotherapeutic Approaches to Common Dermatologic Conditions. Archives of Dermatology, 134, 1401-1404. https://doi.org/10.1001/archderm.134.11.1401

[12] Takenaka, H., Mikoshiba, S., Ishimaru, H., Someya, K., Hayashi, T. and Takada, K. (2004) Analysis of Isovaleric Acid Generation by Skin Resident Microorganism in Body Malodors, and the Inhibitory Effect of Sophora falvescens Extract. Japanese Cosmetic Science Society, 28, 177-182.

[13] Wild, J.E., Bowman, J.P. and Oddo, L.P. (1999) Clinical Evaluation of Anti, Perspirants and Deodorants. In: Laden, K., Ed., Antiperspirants and Deodorants, 2nd Edition, Marcel Dekker, New York, 305-326.

[14] Murphy, T.D. and Levine, M.J. (1991) Analysis of Antiperspirant Efficacy Test Results. Journal of the Society of Cosmetic Chemists, 42, 167-197.

[15] Natsch, A., Schmid, J. and Flachsmann, F. (2004) Identification of Odoriferous Sulfanylalkanols in Human Axilla Secretions and Their Formation through Cleavage of Cysteine Precursors by a C-S Lyase Isolated from Axilla Bacteria. Chemistry \& Biodiversity, 1, 1058-1072. https://doi.org/10.1002/cbdv.200490079

[16] ISO 17299-2:2014. Determination of Deodorant Property. International Organi- zation for Standardization, Geneva.

http://www.iso.org/obp/ui/\#iso:std:iso:17299:-2

[17] Casellini, C.M., Parson, H.K., Richardson, M.S., Nevoret, M.L. and Vinik, A.I. (2013) Sudoscan, a Noninvasive Tool for Detecting Diabetic Small Fiber Neuropathy and Autonomic Dysfunction. Diabetes Technology \& Therapeutics, 15, 948-953. https://doi.org/10.1089/dia.2013.0129

[18] Gin, H., Baudoin, R., Raffaitin, C., Rigalleau, V. and Gonzalez, C. (2011) Non-Invasive and Quantitative Assessment of Sudomotor Function for Peripheral Diabetic Neuropathy Evaluation. Diabetes \& Metabolism, 37, 527-532. https://doi.org/10.1016/j.diabet.2011.05.003

[19] Roe, B., Flanagan, L., Jack, B., Barrett, J., Chung, A., Shaw, C., et al. (2011) Systematic Review of the Management of Incontinence and Promotion of Continence in Older People in Care Homes: Descriptive Studies with Urinary Incontinence as Primary Focus. Journal of Advanced Nursing, 67, 228-250.

https://doi.org/10.1111/j.1365-2648.2010.05481.x

[20] Leyden, J.J., McGinley, K.J., Hölzle, E., Labows, J. and Kligman, A.M. (1981) The Microbiology of the Human Axilla and Its Relationship to Axillary Odor. Journal of Investigative Dermatology, 77, 413-416. https://doi.org/10.1111/1523-1747.ep12494624

[21] Rhee, I.K., van de Meent, M., Ingkaninan, K., Verpoorte, R. (2001) Screening for Acetylcholinesterase Inhibitors Using Silica Gel Chromatography in Combination with Bioactive Staining. Journal of Chromatography A, 915, 217-223. https://doi.org/10.1016/S0021-9673(01)00624-0

[22] Leung, P.C., Hui, P.C.L., Ng, F.S.F., Lau, C.B.S., Cheng, K.F., Lo, W.W.M., et al. (2016) Evaluation of the Topical Antiperspirant Effects of a Simple Herbal Formula. Clinical and Medical Investigations.

https://oatext.com/Evaluation-of-the-topical-antiperspirant-effects-of-a-simple-her bal-formula.php\#Article

[23] Cheater, F.M., Baker, R., Gillies, C., Wailoo, A., Spiers, N., Reddish, S., et al. (2008) The Nature and Impact of Urinary Incontinence Experienced by Patients Receiving Community Nursing Services: A Cross-Sectional Cohort Study. International Journal of Nursing Studies, 45, 339-351. https://doi.org/10.1016/j.ijnurstu.2006.09.006 
Submit or recommend next manuscript to SCIRP and we will provide best service for you:

Accepting pre-submission inquiries through Email, Facebook, LinkedIn, Twitter, etc. A wide selection of journals (inclusive of 9 subjects, more than 200 journals)

Providing 24-hour high-quality service

User-friendly online submission system

Fair and swift peer-review system

Efficient typesetting and proofreading procedure

Display of the result of downloads and visits, as well as the number of cited articles Maximum dissemination of your research work

Submit your manuscript at: http://papersubmission.scirp.org/

Or contact aar@scirp.org 